\title{
A Review of Power Converter Topologies with Medium/High Frequency Transformers for Grid Interconnection Systems
}

\author{
Usman Nasir, Member, IEEE, Marco Rivera, Member, IEEE, Sergio Toledo, Member, IEEE \\ Alessandro Costabeber, Member, IEEE and Patrick Wheeler, Member, IEEE
}

\begin{abstract}
In recent years, power electronics has evolved dramatically due to their importance in power extracted management from renewable sources. In this paper an overview of grid interconnection systems with galvanic isolation is presented. The most common used topologies from AC/AC, AC/DC, DC/AC and AC/AC conversion are analyzed y summarized in order to provide a good understanding of the existing technologies.
\end{abstract}

Index Terms-Grid interconnection, Power converters, Galvanic Isolation

\section{INTRODUCTION}

$\mathbf{T}$ ODAY, an increased penetration of Renewable Energy Sources (RES) and other Distributed Energy Sources (DES) has been seen and power electronic converters play a crucial role by providing the interconnection of these energy sources. The efficiency of the overall interconnection system or Future Electricity Network (FEN) will largely depend on the efficiency of the power converter. Therefore, different $\mathrm{AC} / \mathrm{AC}$ power converter architectures and configurations must be investigated for this purpose. The AC/AC power converter architectures will be evaluated based on the requirements from power converter in FEN such as bi-directional power flow capability, flexibility and reliability [1], [2]. In addition to these requirements, the power converter should also possess the following requirements:

- Galvanic isolation: technologies of converter, such as matrix converters, offer a direct conversion of $\mathrm{AC} / \mathrm{AC}$ with a high power density as the overall size of the converter decreases by avoiding the large energy storage components but unfortunately, such converters are not much useful in the applications which are more prone to faults [3]. In such applications, it is highly required to have galvanic isolation between the input and the output side of the converters and an example of such a system is Universal Flexible Power Management (UNIFLEX-PM) [1], [3]. Since, such a power converter has a large number of semiconductor devices [2], therefore without galvanic isolation, an occurrence of a fault can cause an excessive current flow through the semiconductor devices which

U. Nasir, A. Costabeber and P. Wheeler are with the Department of Electrical Engineering, Faculty of Engineering, The University of Nottingham, Nottingham, UK e-mail: Alessandro.Costabeber@nottingham.ac.uk.

M. Rivera, and S. Toledo are with the Department of Electrical Engineering, Faculty of Engineering, Universidad de Talca, Curicó, PB, 3341717 CHILE e-mail: marcoriv@utalca.cl (see https://marcorivera.cl/).

9781509011476/16/\$31.00@2016IEEE can possibly destroy expensive equipment on both the input and the output sides of the converter. Although the galvanic isolation can be provided by employing a line frequency transformer at the output of the power converter, but the transformer operating at line frequency is expensive, bulky and heavy [4], [5]. Hence, by employing the line frequency transformer with the converter, the idea to reduce overall size of the converter becomes vague. A compact and cost effective solution is to employ a Medium Frequency/High Frequency (MF/HF) transformer in between the two power converters. Therefore, the $\mathrm{MF} / \mathrm{HF}$ isolated power converter architectures are proposed.

- Bidirectional power flow capability: in order to make the power converters usable in the FEN, the converters with bi-directional power flow capability are considered only and this is due to the fact that European region is looking towards liberalizing the electricity market which will allow different distributed system operators (DSOs) and multiple transmission system operators (TSOs) to operate on the same electrical network system [2]. The idea of utilizing power electronics in such a network with bi-directional power flow leads to developing and studying new isolated power converter topologies which will allow a better interconnection of the whole FEN.

- Flexibility and scalability: the interconnection and integration of different distributed energy sources (DES), demanding different power and voltage levels, require the structure of converter to be flexible and scalable. This implies that the structure of each module remains the same but it can provide a parallel or a series connection of the cell depending on the requirements from the DES. Therefore, a modular or cellular architecture is proposed [1].

- Easy maintenance and low cost: it is expected that the modular architecture will also require minimum maintenance and the topologies should avoid the large components such as electrolytic DC-link capacitor and line frequency transformers to help the overall converter to have decreased cost and an increased life time.

- Compact power conversion and low weight: in order to have high power density, the topologies of converters such as matrix converters with isolation must be given special consideration.

- High efficiency and reliability: in addition to the afore- 
mentioned constraints, the converter must be able to provide a high efficiency with acceptable performance and the specifications such as modular structure will increase the reliability.

This paper discusses the possible $\mathrm{MF} / \mathrm{HF}$ isolated $\mathrm{AC} / \mathrm{AC}$ architectures and the evolution of a new isolated $\mathrm{AC} / \mathrm{AC}$ topology. The new isolated AC/AC topology can serve as a potential candidate for Future Electricity Network (FEN) because it combines the advantages of matrix converters with those of modular converters, providing high modularity and scalability, reduced weight and volume, minimum number of conversion stages and minimum energy storage.

\section{Evolution OF MF/HF LinK AND GALVANiC ISOLATION}

Matrix converter offers an all silicon solution for AC/AC conversion systems. Unlike a typical IGBTs based conventional voltage source converter, the matrix converter does not have large energy storage components [6]. The overall size of the converter considerably reduces by removing the large energy storage components but unfortunately, there is no galvanic isolation. In case of fault, an excessive current can possibly destroy expensive equipment and semiconductor devices especially in medium and high power applications.

There is no doubt that, the galvanic isolation can be provided by employing a line frequency transformer, at the output of the matrix converter, that can even step-up or stepdown the primary voltage of the transformer in accordance with the turns ratio present between primary and secondary side of the transformer and can also provide galvanic isolation when connected with a matrix converter but a line frequency transformer is bulky in size and the idea of reducing the overall size of the converter equipment becomes vague. Therefore, there is a need for power converter topology which gives special considerations to galvanic isolation and compact size.

In electrical distribution system, a line transformer is one of the heaviest and expensive equipment due to the bulky iron core and heavy copper windings [5]. Therefore, increasing the frequency will either allow a reduction in the core area or winding area, which in turn decreases the size of the transformer [7]. The concept of introducing a high frequency (much higher than line frequency of $50 \mathrm{~Hz}$ or $60 \mathrm{~Hz}$ ) transformer in power conversion (AC/AC, DC/DC AC/DC or vice versa) is usually referred in literature as high-frequency-link or $A C$ link. The high frequency link in the power conversion leads to the following main advantages:

- A significant reduction in the size and weight of the transformer.

- Electrical/galvanic isolation.

It is interesting to mention that an AC-link is a dual of a DClink just as an inductor is a dual of capacitor due to that fact that a capacitor always try to oppose the change in the voltage whereas the same statements holds true by inductor for the change in current. Ideally, a voltage source is stiff with respect to voltage such that no matter how much current a load draws, the voltage remains constant but in reality, a high valued capacitance is usually connected in parallel to the voltage source to increase the stiffness of the voltage. For instance, in a Voltage Source Converter (VSI) a bulky capacitor is usually added to provide the DC-link. Similarly, an inductor is added in series with a current source. For example, in order to realize a Current Source Inverter (CSI), a large inductor is connected in series with the current source. As a current source imposes the current regardless of the voltage across its terminals, this implies that the series impedance of a current source should be infinite. Therefore, the impedance of a high frequency AClink with low inductance value is same as the low frequency AC-link with a high value of inductance. So, the concept of high frequency AC-link helps in reducing the weight and size of the transformer. Conversely, by connecting an inductor in series to the voltage source, give rise to the concept of source transformation from a voltage source to current source. Hence, the mentioned concepts are dual in nature, so a transformation of a current source to a voltage source is also feasible. Penetration of the distributed energy sources, including renewable energy sources and energy storage systems, demands a bidirectional power flow capability from the power converters. In order to make the power converters usable in the future electrical network, the converters with bi-directional power flow capability must be considered only and this is due to the fact that European region is looking towards liberalizing the electricity market which will allow different distributed system operators (DSOs) and multiple transmission system operators (TSOs) to operate on the same electrical network system [2]. The idea of utilizing power electronics in such a network with bi-directional power flow leads to developing and studying new isolated power converter topologies which will allow a better interconnection of the whole FEN. A study has been done under the European frame work under the name of UNIFLEX-PM in Future Electrical Grids. In this paper will be presented a discussion regarding the different cases of power conversion via Medium/High Frequency AC-link which can be $\mathrm{DC} / \mathrm{DC}, \mathrm{AC} / \mathrm{DC}, \mathrm{DC} / \mathrm{AC}$ and then finally $\mathrm{AC} / \mathrm{AC}$.

\section{Types OF MOdulaR TOPOLOGIES WITH MF/HF LINK}

Considering bi-directional power flow, modular architectures and galvanic isolation in a AC distribution system, the possible power converter configurations for the future grid can be $\mathrm{AC} / \mathrm{DC} / \mathrm{AC}$ via $\mathrm{MF} / \mathrm{HF}$ link between $\mathrm{DC} / \mathrm{AC}$ stage, $\mathrm{AC} / \mathrm{DC} / \mathrm{DC} / \mathrm{AC}$ via $\mathrm{MF} / \mathrm{HF}$ link between $\mathrm{DC} / \mathrm{DC}$ stage or $\mathrm{AC} / \mathrm{AC}$ via $\mathrm{MF} / \mathrm{HF}$ link. The mentioned cell architectures are shown in Fig. 1 to Fig. 3.

Fig. 1 shows the single isolated AC/DC/DC/AC cell comprising of four H-bridges with two DC-link capacitors therefore, making a total of three power stages whereas Fig. 2 shows the isolated AC/DC/AC cell comprising of two $\mathrm{H}$ bridges and one cyclo-converter based module (CBM) with one DC-link capacitor, therefore the total number of power conversion stages decrease to two. Fig. 3 shows the cell architecture of an isolated $\mathrm{AC} / \mathrm{AC}$ direct converter and this type of architecture does not need DC-link capacitors unlike the other two architectures. Up till now, a comprehensive study has been done on the first two mentioned architectures i.e. $\mathrm{AC} / \mathrm{DC} / \mathrm{DC} / \mathrm{AC}$ or $\mathrm{VSIBM}$ and $\mathrm{AC} / \mathrm{DC} / \mathrm{AC}$ or $\mathrm{CBM}$ for 


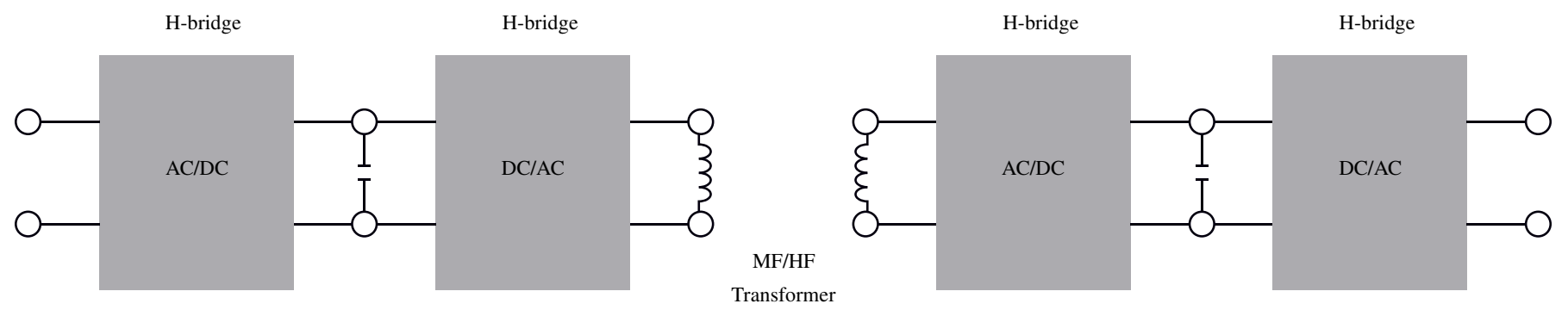

Fig. 1. Isolated AC/DC/DC/AC (VSIBM) cell.

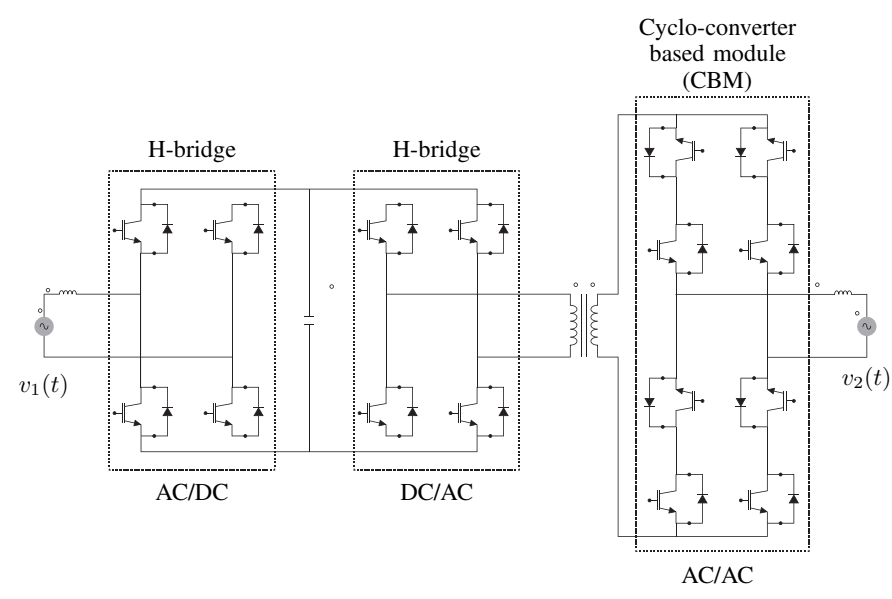

Fig. 2. Isolated $\mathrm{AC} / \mathrm{DC} / \mathrm{AC}(\mathrm{CBM})$ cell.

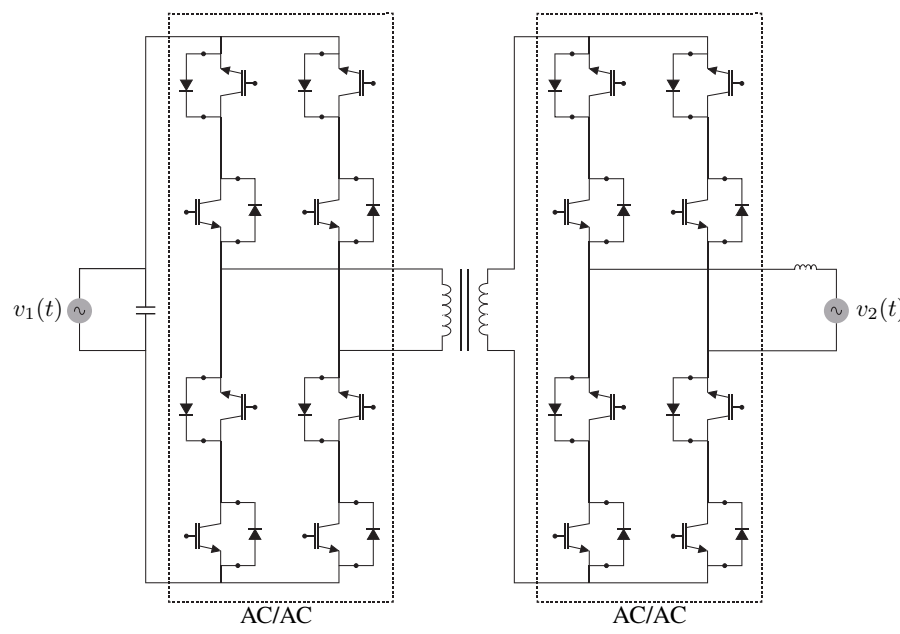

Fig. 3. Isolated AC/AC direct converter cell.

UNIFLEX in the last 6 years. Reference [8] discusses the implementation and comparison of $25 \mathrm{kVA}$ rated converters of architectures shown in Fig. 1 and Fig. 2 and this paper provides a brief overview of the said comparative study.

\section{A. Isolated AC/DC/DC/AC cell architecture}

The principle of operation of this type of cell i.e. active power flow is based on the DC/DC dual active bridge and the DC-link voltages regulation is provided through the grid side converters. An isolated DC/DC dual active bridge converter

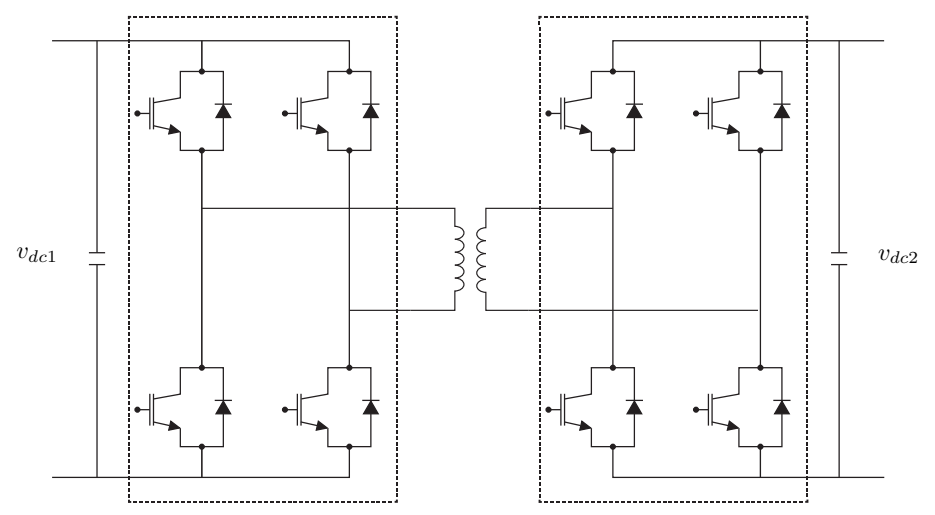

Fig. 4. Isolated DC/DC dual active bridge converter.

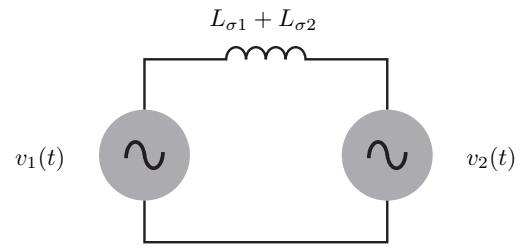

Fig. 5. Simplified MF transformer model for DC/DC dual active bridge.

is shown in Fig. 4. The active power flow control is achievable by applying the phase shift $\delta$ between the primary and secondary voltages in the DC/DC dual active bridge. In order to understand the working of the DC/DC dual active bridge, one must have the prior knowledge about the interconnection of different voltage sources, such as a voltage source can be directly connected to a current source but a voltage source cannot be directly connected to another voltage source [9], therefore, the leakage inductance of the transformer helps to provide the interconnection of the two voltage sources as shown in Fig. 5. This type of control is not difficult to implement and a lot of work has been done on this. A detailed study and design of the DC/DC dual active bridge converter has been done in [10], [11]. In short, by varying the phase shift between the secondary voltage and the primary voltage of the transformer, the direction and the amplitude of the current passing through the leakage inductance is controlled [12]. For instance, when $v_{p}=v_{s}$ and if $v_{s}$ is leading $v_{p}$, then the component of the $v_{s}$ in the direction of $v_{p}$ will be smaller implying that the direction of the power flow will be from $v_{s}$ to $v_{p}$. Therefore, by changing the phase shift $\delta$ while $v_{s}$ leads 
$v_{p}$, the amount of active power flow (from $v_{s}$ to $v_{p}$ ) can be changed whereas by changing the phase shift $\delta$ while $v_{s}$ lags $v_{p}$, the amount of active power flow (from $v_{p}$ to $v_{s}$ ) can be changed. Reference [8] has also employed snubber capacitors in parallel with the IGBTs to help the switches turn off with the reduced value of current. It must also be noted that the antiparallel diodes with the IGBTs allow the IGBTs to turn on with reduced value of voltage. Ideally, at turn off, the current flowing through the switch goes to zero before the voltage appears across it but in reality, the current takes some time to go to zero and due to this there exist an overlap between the current and the voltage, therefore leading to switching losses. This phenomenon is often referred to as hard switching and this happens due to the fact that the intrinsic region holds the charges for some time even after gating signal of the device has gone to zero i.e. even after the device has been switched off [13]. Therefore, connecting a capacitor in parallel to the switch will always help the device to have lesser turn off losses therefore, this phenomenon, in literature, is usually referred to as soft switching or zero voltage switching (ZVS). Reference [13] illustrates the difference between hard and soft switching. Switching losses considerably increase with the increase of the switching frequency as the turn on and turn off phenomenon happens frequently. At this moment, the further discussion of ZVS for DC/DC converter is not of interest. The complete switching sequence of the DC/DC converters can be found in [8].

1) Summary of the topology:

- Control is possible by having phase shift between transformer voltage primary voltage $v_{p}$ and secondary voltage $v_{s}$.

- Easiest with respect to modulation and commutation i.e. dead-time commutation.

- Contains energy storage components i.e. two DC-link capacitors.

- Design of isolation module is comparatively easier than other two AC/AC solutions.

- Isolation module has core losses of about $3.9 \mathrm{~W} / \mathrm{kg}$ and ohmic losses of $7 \mathrm{~W} / \mathrm{kg}$, respectively for a $61.6 \mathrm{kVA}$ transformer with rated current of $56 \mathrm{~A}$ and the overall efficiency of $95.5 \%$ claimed at $2000 \mathrm{~Hz}$ [8].

- Isolation module has higher short circuit impedance.

- Semiconductor losses are lesser in this architecture in comparison to other two solutions.

\section{B. Isolated AC/DC/AC cell architecture}

The principle of operation of this type of cell i.e. power flow is based on the DC/AC CBM and the DC-link voltage regulation is provided through the grid side inverter. An isolated DC/AC CBM shown in Fig. 6. Each bidirectional switch of CBM is bi-directional with respect to current as well as bidirectional with respect to voltage [9]. Therefore, the switch has a four-quadrant operation. In [12], the AC side is considered as a stiff current source while the DC side behaves as the voltage source (Fig. 6). The control scheme has been developed and implemented in [12]. The main idea of this type of control is that the voltage at the AC side can be varied

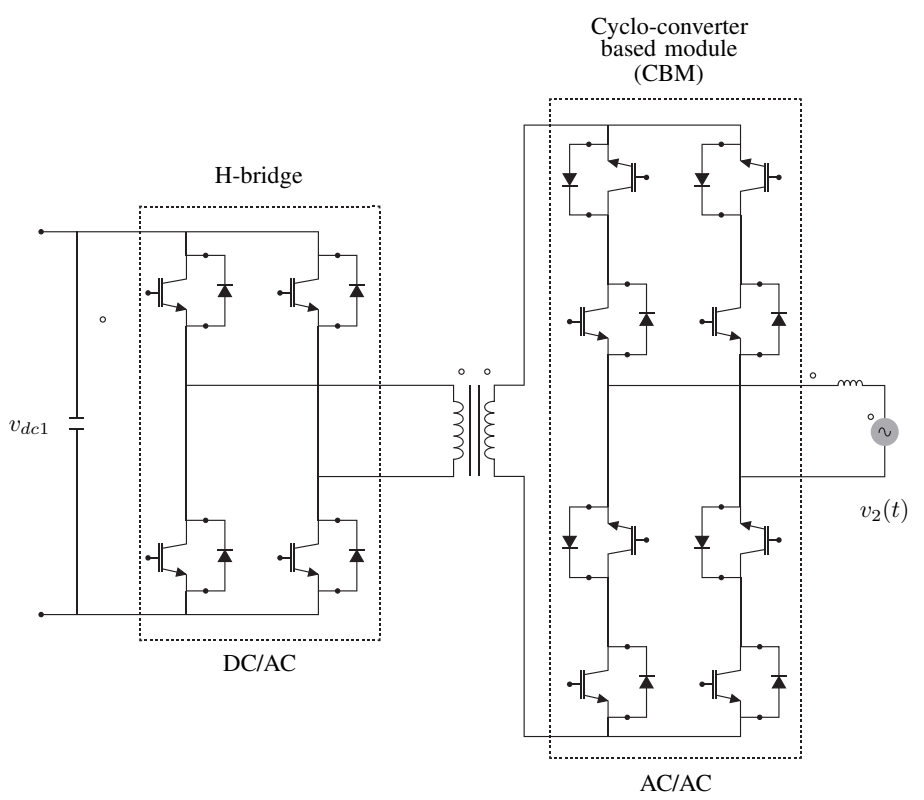

Fig. 6. Isolated DC/AC with Cyclo-converter based module (CBM).

regardless of the voltage of the transformer. The phase shift $\tau$ between the AC voltage and the voltage at the transformer which in turn makes the transformer current to delay with respect to the transformers voltage. This type of control can result in a two level or a three level modulated AC voltage i.e. for two level modulation $V_{c}$ can have $-1,+1$ and for three level modulation $V_{c}$ can have $-1,0,+1$ [13]. Improvements in decreasing the switching losses can be made by adding the snubber capacitors on the VSI side and by adding a snubber inductance on the CBM side (secondary side of transformer) to help the devices of VSI with ZVS operation and CBM with ZCS operation, respectively. It should be mentioned that the mathematical modelling of the snubber inductance $L_{f}$ and the snubber capacitance $C$ is explained in detailed in [12]. Reference [14] has demonstrated a two-cell multilevel approach of the DC/AC with CBM converter by connecting the two CSI cells in series at AC side and VSI in parallel at DC side as shown in Fig. 7 [14]. In comparison to AC/DC/DC of Fig. 1, AC/DC with CBM offers a lower voltage resolution at the output but similar voltage resolution can be obtained at the expense of commutation losses [13], [14]. As mentioned earlier, study in [8] has compared the two topologies of DC/DC dual active bridge and DC/AC of Fig. 4 and Fig. 6 respectively. The key features of the comparative study were based on the design of the MF transformer and conduction losses. Since, both topologies are different in operation, the requirement for the MF transformer for both of these are quite different. For instance in DC/AC architecture, one side has a VSI and the other side has CSI, the side with CSI required the short circuit impedance of the transformer to be as small as possible in order to avoid losses:

$$
B_{\text {max }} \alpha \frac{U}{N A_{c} f}
$$

where $B_{\max }$ correspond to the maximum allowed core magnetic flux density, $U$ the applied voltage, $N$ the number of 


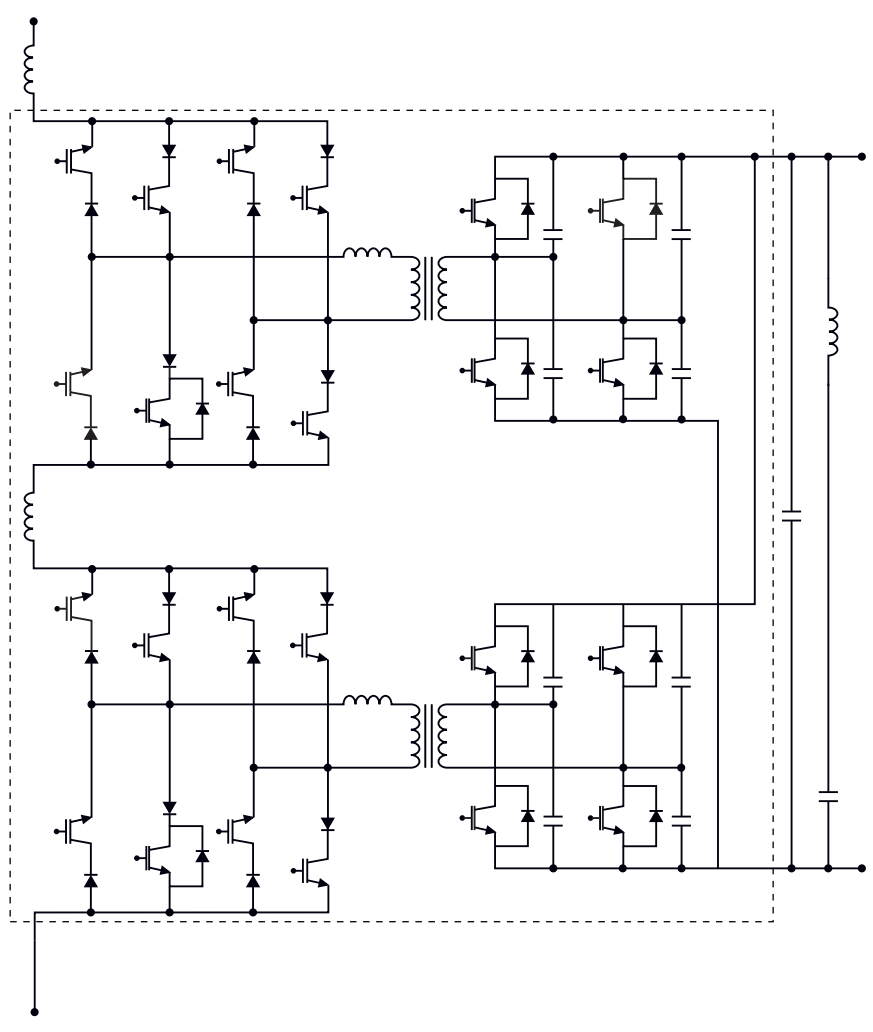

Fig. 7. Simplified scheme of a two-cell multilevel AC/DC with CBM for traction applications.

turns, $A_{c}$ the cross-sectional area of core and.$f$ the operating frequency of transformer. Increasing the operating frequency of the transformer can help to decrease $A_{c}$ but CBM based DC/AC converter demands the transformer to have a small short circuit impedance and this can be achieved by decreasing the number of turns $N$ but consequently, the cross sectional area $\mathrm{AC}$ of the transformer increases. This leads to higher core losses than the transformer for VSIBM. Therefore in [8], a dual core has been employed to concentrate the leakage field within the core.

$$
P_{\text {core }}=k f^{x} B^{y} V_{e}
$$

where $P_{\text {core }}$ correspond to the core losses of the transformer, $k$ the constant of the core material, $f$ the operating frequency in $\mathrm{kHz}, y$ the flux density exponent, $x$ the frequency exponent and $V_{e}$ the effective core volume. Therefore, the core losses in the transformer for CBM will be higher than in a transformer for VSIBM whereas the ohmic losses will be lower for CBM than as compared to VSIBM because CBM employs the transformer with lesser number of turns $N$ [8]. The CSI side in CBM DC/AC converter has higher conduction losses due to a high count of power semiconductor devices in comparison to VSI side. In [8] it shows the comparative analysis of VSIBM, CBM-2n and CBM-3n in terms of semiconductor losses, with approximately $2.5 \%, 3.75 \%$ and $3.45 \%$, respectively. It must be noted that in case of CBM, the conduction losses are contributing towards most of the semiconductor losses. If possible, it is suggested to use reverse-blocking IGBTs in order to avoid the diodes in a four-quadrant switch [13]. Also, in [8] it illustrates the comparison of the isolation modules i.e.

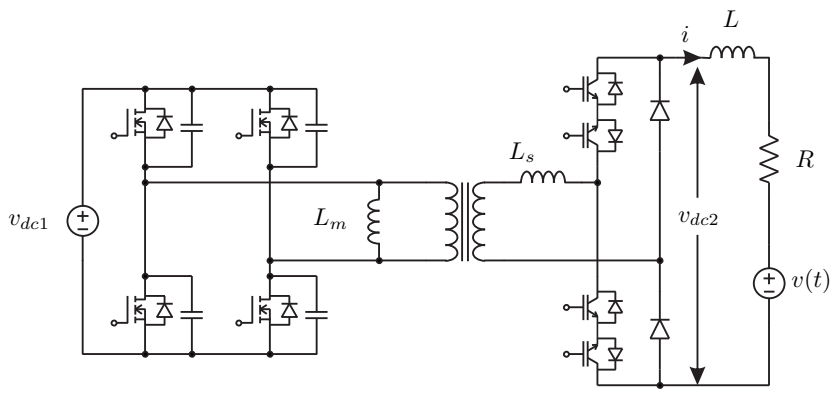

Fig. 8. Method to decrease conduction losses in CBM isolate DC/AC converter.

MF transformer. Efficiency for VSBM, CBM-2n and CBM$3 \mathrm{n}$ are approximately $95 \%, 93 \%$ and $94 \%$, respectively. In comparison to VSIBM, the increased core losses in CBM cause the efficiency of MF transformer to decrease. Therefore, the overall efficiency of the DC/AC with CBM decreases in comparison to DC/DC/AC with VSIBM [8]. Reference [15] has explained a method to decrease the conduction losses by providing a smaller circuit path for the current to flow such as shown in Fig. 8. If $i_{A}$ is positive and $u_{\text {reci }}$ is positive or if $i_{A}$ is negative and $u_{\text {reci }}$ is negative then this method can work but when either of them has opposite polarity, this method is not useful. [16] discusses and presents a comparison between the commutation of the switches in DC/AC CBM with conventional naturally commutated devices and self-turn off devices. Moreover, a modulation method, using saw tooth carrier signal is also explained in [17].

1) Summary of the topology:

- Two types of control i.e. two-level or three-level control by phase shift between transformer voltage $V_{t}$ and output AC voltage $V_{\text {out }}$.

- Comparatively difficult with respect to modulation and commutation i.e. dead-time commutation on VSI side bridge and multi-step commutation on CBM side.

- Contains energy storage components i.e. one DC-link capacitor.

- Design of isolation module is comparatively difficult than the previous solution.

- Isolation module has core losses of about $5 \mathrm{~W} / \mathrm{kg}$ and ohmic loses of $3 \mathrm{~W} / \mathrm{kg}$, respectively for a $36.3 \mathrm{kVA}$ with rated current of $33 \mathrm{~A}$ and overall efficiency of $94.5 \%$ at $2000 \mathrm{~Hz}$ was claimed in [8].

- Isolation module needs lower short circuit impedance.

- Semiconductor losses are higher in this architecture in comparison to the previous solution.

\section{Isolated AC/AC (direct) cell architecture}

There has also been some work on the single phase matrix AC/AC converter shown in Fig. 9 i.e. considering only one part of the cell of Fig. 3. The cell of Fig. 9 can also be used in the applications where the desired output frequency is different than input but unfortunately, the galvanic isolation is not present. Although, some improvement in the commutation strategy of [18] has been done in [19] by providing the load current a free-wheeling path but in order to obtained 


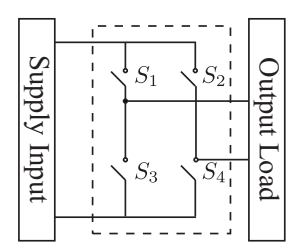

Fig. 9. Single phase AC/AC converter.

an output with lesser THD, the cell of Fig. 9 must be provided with a high frequency link and galvanic isolation otherwise said topology is not of practical importance for high power grid interconnection applications. Therefore, the scheme of Fig. 3 (with galvanic isolation) will be discussed. Fig. 3 shows an AC/AC converter with high frequency link present between the two bridges. Since, in a VSI the voltage source is unidirectional i.e. not alternating and the current through the source is bidirectional, anti-parallel diodes with IGBTs can serve the purpose in providing a bidirectional path for the current [20] but in case of alternating voltage and alternating current, the switches must be not only be bidirectional with respect to current but the switches should also be bidirectional with respect to voltage. Considering the $\mathrm{AC}$ grid as a stiff current source, this type of converter cell provides the interconnection of two current sources (via high frequency link) while behaving as CSI. This type of cell helps in removal of the bulky DC-link capacitors. One step power conversion using conventional cyclo-converters based on naturally commutated devices has been used for decades. The converter architecture of Fig. 3 was initially presented by Paul M. Espelage et.al in 1977 which was based on thyristors [21] but it should be mentioned that the research on the AC/AC converters is mainly limited to naturally commutated converters or non-isolated matrix converters [22]. Moreover, the turn off time $t_{q}$, of the thyristors, puts a limit on the frequency. Therefore in 1988, Pradeep K. Sood et.al implemented the high frequency link with a three phase converter made of fourquadrant self-commutated switches (instead of thyristors) to derive motor/generator. Daolian Chen, in [23] and in [24], has shown different topologies of the converter cell for isolated AC/AC conversion. The converter cell of Fig. 3 has been shown in [23] but the detailed bi-polarity voltage mode control and commutation has only been developed for isolated full bridge-full wave converter AC/AC. The term bipolarity is referred to the output $\mathrm{AC}$ voltage with respect to the bipolar voltage at the high frequency link. The bipolar voltage mode control is not suggested because of the bad frequency spectrum [23], [24]. Therefore, a unipolar voltage mode control was proposed in [25] and the basic idea of the this type of voltage mode control is that the high frequency bipolarity three state $(-1,0,+1)$ voltage at the transformer is demodulated to a unipolar output AC voltage. Therefore, the polarity of the output AC voltage remains same till half of the desired output period. The modulation scheme has been developed using a saw tooth wave as a carrier signal with sine wave signal. The THD and efficiency obtained by unipolar voltage mode control is claimed to be $\leq 4 \%$ and $80 \%-85.3 \%$. The complete switching sequence and design has been explained in [25]. In 2008, a current mode control, for a full bridge-full wave isolated $\mathrm{AC} / \mathrm{AC}$ converter, was presented in [26]. In the current mode control, the input voltage is converted into a high frequency ripple current instead of high frequency voltage. Lei li, in [27], has compared the two controls i.e. voltage mode control and current mode control for the said converter. Power flow control in the voltage mode control is obtained by phase shift method whereas in current mode the power flow control is obtained by instantaneously controlling the transformer current. Although, the current control mode is much easier to implement but the switches in current mode operate under hard switching whereas the voltage mode control is difficult to realize but it can offer advantages such as ZVS and suitability for high power applications. A very simple hard switching based control strategy has been presented in [28] and a careful design of MF transformer is suggested i.e. using a dual core transformer as in [8] to minimize the leakage inductance and proximity effect but the core losses are approx. $3.2 \mathrm{~W} / \mathrm{kg}$ and the efficiency of transformer was claimed to be $98 \%$ at 1000 $\mathrm{Hz}$ [28]. It should be noted that the core losses in [8] were about $4.8 \mathrm{~W} / \mathrm{kg}$, therefore the cell under study was not selected for UNIFLEX. An input voltage reference mode and output current reference mode controls are discussed in detail in [28] for the cell shown in Fig. 3. The voltage reference mode works on considering the sign of input voltage as a reference and whereas, the current reference mode works on considering the sign of the output current reference. Since, the current at the load side and voltage at the input side are at low frequency, the current reference control has been implemented on the output side converter whereas the voltage reference control has been implemented on the input side converter. The commutation strategy implemented in [28] is the extended version of the conventional four-step commutation explained in [3], [29] and the evolution of the commutation strategy is based on the two rules i.e. the voltage source must never be short circuited and the current source/load must not be open circuited. Interrupting the current of the load will result in the very high voltage spikes due to the abrupt change in the current and the dual of this situation happens by shorting the voltage source. In the first case, the valves or switching devices will come under high voltage stress whereas in the second case, the switching devices will have an excessive current/over current.

1) Summary of the topology:

- Very difficult with respect to modulation and commutation i.e. multi-step commutation on both bridges.

- Two types of control for each part of circuit i.e. current reference control voltage reference control.

- Single power stage.

- Energy storage component i.e. no DC-link capacitor is not required and switching pattern must be carefully designed to avoid open circuiting the load.

- Design of isolation module is comparatively difficult than other two AC/AC solutions.

- Optimized design of isolation module can help to decrease the core losses and hence, overall efficiency can be improved.

- Isolation module has core losses of about $3.2 \mathrm{~W} / \mathrm{kg}$ and ohmic loses of $2.4 \mathrm{~W} / \mathrm{kg}$, respectively for a 10 
kVA transformer with rated current of $15 \mathrm{~A}$ and overall efficiency of $98 \%$ at $1000 \mathrm{~Hz}$ was claimed in [28].

- Semiconductor losses are assumed to be same or higher, in this architecture in comparison to the previous solutions.

\section{CONCLUSIONS}

This paper discussed the possible isolated MF/HF-link AC/AC cells and a comparative analysis has been presented based on the literature review. The efficiency of the whole cell is largely dependent on the efficiency of the isolation module. VSIBM and CBM has been experimentally compared in [8] and there is a need to compare direct topology with the said topologies. Direct topology offers a decrease in the DC-link capacitors but this comes at an increased difficulty in modulation and commutation. Based on the summarized points, the direct $\mathrm{AC} / \mathrm{AC}$ solution has provided promising efficiency but the said solution has not been given importance due to extreme complexity in implementation in commutation and modulation but now with the advancement in the technology of processors i.e. DSPs and FPGAs, the direct AC/AC solution has the potential to emerge as a viable candidate. Therefore, there is a need to explore new modulation, commutation and control methods. In short, this paper has provided a brief overview of present $\mathrm{AC} / \mathrm{AC}$ solutions with an emphasis on the direct $\mathrm{AC} / \mathrm{AC}$ solution.

\section{ACKNOWLEDGMENTS}

This publication was made possible by the FONDECYT Regular 1160690, the Newton Picarte Project EPSRC: EP/N004043/1: New Configurations of Power Converters for Grid Interconnection Systems / CONICYT DPI20140007 and the CONACYT project 14-INV-097.

\section{REFERENCIAS}

[1] J. Clare, "Advanced power converters for universal and flexible power management in future electricity networks," Power Electronics and Applications, 2009. EPE '09. 13th European Conference on, Barcelona, Spain, 2009, pp. 1-29.

[2] S. Bifaretti, P. Zanchetta, Yue Fan, F. Iov and J. Clare, "Power flow control through a multi-level H-bridge based power converter for Universal and Flexible Power Management in future electrical grids," Power Electronics and Motion Control Conference, 2008. EPE-PEMC 2008. 13th, Poznan, 2008, pp. 1771-1778. doi: 10.1109/EPEPEMC.2008.4635522.

[3] P. W. Wheeler, J. Rodriguez, J. C. Clare, L. Empringham and A. Weinstein, "Matrix converters: a technology review," in IEEE Transactions on Industrial Electronics, vol. 49, no. 2, pp. 276-288, Apr 2002. doi: $10.1109 / 41.993260$

[4] H. Yonemori, Y. Nishida and M. Nakaoka, "New bidirectional sinewavemodulated series resonant power conditioning system with high-frequency AC-link," Telecommunications Energy Conference, 1989. INTELEC '89. Conference Proceedings., Eleventh International, Florence, 1989, pp. 14.2/1-14.2/6 vol.2. doi: 10.1109/INTLEC.1989.88299.

[5] M. D. Manjrekar, R. Kieferndorf and G. Venkataramanan, "Power electronic transformers for utility applications," Industry Applications Conference, 2000. Conference Record of the 2000 IEEE, Rome, 2000, pp. 2496-2502 vol.4. doi: 10.1109/IAS.2000.883173.

[6] P. Wheeler, J. Clare, L. Empringham, M. Apap and M. Bland, "Matrix converters," in Power Engineering Journal, vol. 16, no. 6, pp. 273-282, Dec. 2002. doi: 10.1049/pe:20020601.

[7] S. D. Sudhoff, Solid state transformer,to Google Patents, 1999. http://www.google.com/patents/US5943229
[8] D. Siemaszko, F. Zurkinden, L. Fleischli, I. Villar, Y. R. De Novaes, and A. Rufer, "Description and Efficiency Comparison of Two $25 \mathrm{kVA}$ DC/AC Isolation Modules," EPE Journal, vol. 19, no. 4, pp. 17-24, 2009/12/01, 2009. doi:10.1080/09398368.2009.11463733.

[9] Y. Cheron. 1992. Soft Commutation, Chapman \& Hall, London, 233 pages.

[10] C. Mi, H. Bai, C. Wang and S. Gargies, "Operation, design and control of dual H-bridge-based isolated bidirectional DC-DC converter," in IET Power Electronics, vol. 1, no. 4, pp. 507-517, December 2008. doi: 10.1049/iet-pel:20080004.

[11] S. Z. M. Noor, M. K. Hamzah, R. Baharom and N. Y. Dahlan, "A New Single-Phase Inverter with Bidirectional Capabilities Using Single-Phase Matrix Converter," 2007 IEEE Power Electronics Specialists Conference, Orlando, FL, 2007, pp. 464-470. doi: 10.1109/PESC.2007.4342032.

[12] C. Chabert, and A. Rufer, "Multilevel converter with 2 stageconversion," European Power Electronics Conference EPE 2001, vol. 4, pp. C3, 2001.

[13] S. Norrga, "On soft-switching isolated AC/DC converters without auxiliary circuit," KTH, Stockholm, 2005.

[14] A. Rufer, N. Schibli, C. Chabert and C. Zimmermann, "Configurable front-end converters for multicurrent locomotives operated on $162 / 3 \mathrm{~Hz}$ AC and $3 \mathrm{kV}$ DC systems," in IEEE Transactions on Power Electronics, vol. 18, no. 5, pp. 1186-1193, Sept. 2003. doi: 10.1109/TPEL.2003.816191.

[15] C. Zimmermann, A. Rufer and C. Chabert, "Non-linear properties and efficiency improvements of a bi-directional isolated DC-AC converter with soft commutation," Fourtieth IAS Annual Meeting. Conference Record of the 2005 Industry Applications Conference, 2005., 2005, pp. 1985-1991 Vol. 3. doi: 10.1109/IAS.2005.1518720.

[16] S. Zainal, C. L. Nge, L. S. Toh, and R. Mohd Zulkifli, "Cycloconvertertype high frequency link inverter for photovoltaic application," The Instituion of Engineers, vol. 67, pp. 49-56, March, 2006.

[17] M. Matsui, M. Nagai, M. Mochizuki and A. Nabae, "High-frequency link DC/AC converter with suppressed voltage clamp circuits-naturally commutated phase angle control with self turn-off devices," in IEEE Transactions on Industry Applications, vol. 32, no. 2, pp. 293-300, Mar/Apr 1996. doi: 10.1109/28.491477.

[18] S. B. Mohite and P. K. Gujarathi, "A design and implementation of a novel multimode single phase matrix converter," SPEEDAM 2010, Pisa, 2010, pp. 1227-1230. doi: 10.1109/SPEEDAM.2010.5542053.

[19] Z. Idris, M. K. Hamzah, and M. F. Saidon, "Implementation of SinglePhase Matrix Converter as a Direct AC-AC Converter with Commutation Strategies," Power Electronics Specialists Conference, 2006. PESC '06. 37th IEEE, Jeju, 2006, pp. 1-7. doi: 10.1109/PESC.2006.1712106.

[20] F. Bordry, Power converters : definitions, classification and converter topologies, Warrington, UK, 2004

[21] P. M. Espelage and B. K. Bose, "High-Frequency Link Power Conversion," in IEEE Transactions on Industry Applications, vol. IA-13, no. 5, pp. 387-394, Sept. 1977. doi: 10.1109/TIA.1977.4503428.

[22] Daolian Chen and Lei Li, "Bi-polarity phase-shifted controlled voltage mode AC/AC converters with high frequency AC-link," Power Electronics Specialist Conference, 2003. PESC '03. 2003 IEEE 34th Annual, 2003, pp. 677-682 vol.2. doi: 10.1109/PESC.2003.1218137.

[23] P. K. Sood, T. A. Lipo and I. G. Hansen, "A versatile power converter for high frequency link systems," Applied Power Electronics Conference and Exposition, 1987 IEEE, San Diego, CA USA, 1987, pp. 249-256. doi: 10.1109/APEC.1987.7067159.

[24] Lei Li and Daolian Chen, "Phase-shifted controlled forward mode AC/AC converters with high frequency AC-links," Power Electronics and Drive Systems, 2003. PEDS 2003. The Fifth International Conference on, 2003, pp. 172-177 Vol.1. doi: 10.1109/PEDS.2003.1282748.

[25] C. Daolian, and L. Jian, "The uni-polarity phase-shifted controlled voltage mode AC-AC converters with high frequency AC-link," in IEEE Transactions on Power Electronics, vol. 21, no. 4, pp. 899-905, July 2006. doi: 10.1109/TPEL.2006.876888.

[26] D. Chen, "Novel Current-Mode AC/AC Converters With HighFrequency AC-link," in IEEE Transactions on Industrial Electronics, vol. 55, no. 1, pp. 30-37, Jan. 2008. doi: 10.1109/TIE.2007.896135.

[27] Lei $\mathrm{Li}$ and Qinglong Zhong, "Comparisons of two kinds of AC/AC converters with high frequency link," Industrial Electronics, 2008. IECON 2008. 34th Annual Conference of IEEE, Orlando, FL, 2008, pp. 618-622. doi: 10.1109/IECON.2008.4758025

[28] M. Kang, P. N. Enjeti and I. J. Pitel, "Analysis and design of electronic transformers for electric power distribution system," in IEEE Transactions on Power Electronics, vol. 14, no. 6, pp. 1133-1141, Nov 1999. doi: $10.1109 / 63.803407$. 
[29] L. Empringham, P. W. Wheeler and J. C. Clare, "Intelligent commutation of matrix converter bi-directional switch cells using novel gate drive techniques," Power Electronics Specialists Conference, 1998. PESC 98 Record. 29th Annual IEEE, Fukuoka, 1998, pp. 707-713 vol.1. doi: 10.1109/PESC.1998.701976.

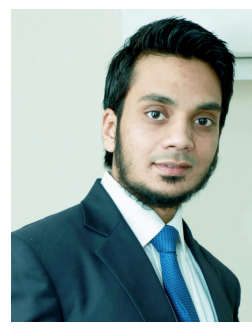

Usman Nasir is currently associated with Power Electronics and Machine Control (PEMC) group at The University of Nottingham, UK as a $\mathrm{PhD}$ student. He is a recipient of Dean of Engineering Scholarship For International Research Excellence for his $\mathrm{PhD}$ studies. He received B.Sc. degree in electrical engineering from the National University of Sciences and Technology (NUST), Pakistan and M.Sc. degree from North China Electric Power University, Beijing, China in 2013 and 2015, respectively. His research interests include new matrix converter based topologies, novel commutation algorithms, new modulation techniques and also Model Predictive Control (MPC) for power electronic converters.

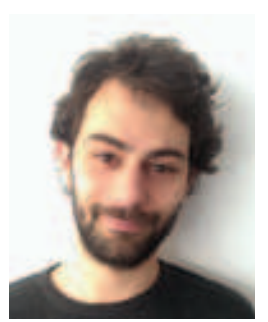

Alessandro Costabeber (S'09-M'13) received the Degree with honours in Electronic Engineering from the University of Padova, Padova, Italy, in 2008 and the Ph.D. in Information Engineering from the same university in 2012, on energy efficient architectures and control techniques for the development of future residential microgrids. In the same year he started a two-year research fellowship with the same university. In 2014 he joined the PEMC group, Department of Electrical and Electronic Engineering, University of Nottingham, Nottingham, UK as Lecturer in Power Electronics. His current research interests include HVDC converters topologies, high power density converters for aerospace applications, control solutions and stability analysis of AC and DC microgrids, control and modelling of power converters, power electronics and control for distributed and renewable energy sources. Dr. Costabeber received the IEEE Joseph John Suozzi INTELEC Fellowship Award in Power Electronics in 2011.

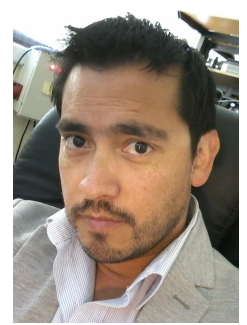

Marco Rivera (S'09-M'11) was born in Talca, Chile, in 1982. He received the B.Sc. degree in electronics engineering and the M.Sc. degree in electrical engineering from the Universidad de Concepción, Concepción, Chile, in 2007 and 2008, respectively, and the Ph.D. degree from the Department of Electronics Engineering, Universidad Técnica Federico Santa María, Valparaíso, Chile, in 2011.

Since 2013 is with the Energy Conversion and Power Electronics Research Group at the Universidad de Talca. He is currently an Associate Professor with the Department of Electrical Engineering at the Universidad de Talca, Curicó, Chile. His main research areas are digital control applied to power electronics, matrix converters, predictive control and control of power converters for renewable energy applications.

Prof. Rivera was recipient of the Best PhD Thesis Award 2012, award given by the Chilean Academy of Science for PhD thesis developed in 2011 by national and foreign students in any Exact or Nature Sciences Program in Chile. In August 2015, Prof. Rivera was awarded with the Outstanding Engineer 2015 Award of the Electrical-Electronics Industry Association and the IEEE-Chile Section and also he received the Second Prize Paper Award in the 2015 IEEE Journal of Emerging and Selected Topics in Power Electronics.

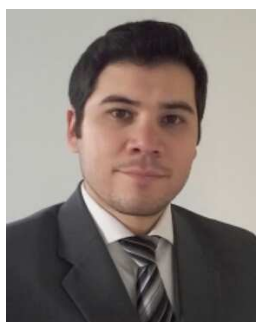

Sergio Toledo (S'09-M'12) was born in Luque, Paraguay in 1985. He received the Electronic Engineer degree from Universidad Nacional de Asunción, Paraguay in 2011 and the M.Sc. degree from Centro de Investigación Científica y Educación Superior de Ensenada, México, in 2014.

Since 2010 he is professor in the Engineering Faculty of Universidad Nacional de Asunción. His research interests include non linear control systems, new converter topologies and control of power converters.

He is currently a Phd student in the Department of Electrical Engineering at the Universidad de Talca, Curicó, Chile.

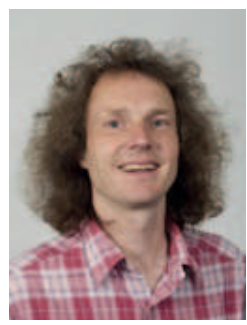

Pat Wheeler received his BEng [Hons] degree in 1990 from the University of Bristol, UK. He received his $\mathrm{PhD}$ degree in Electrical Engineering for his work on Matrix Converters from the University of Bristol, UK in 1994. In 1993 he moved to the University of Nottingham and worked as a research assistant in the Department of Electrical and Electronic Engineering. In 1996 he became a Lecturer in the Power Electronics, Machines and Control Group at the University of Nottingham, UK. Since January 2008 he has been a Full Professor in the same research group. He is currently Head of the Department of Electrical and Electronic Engineering at the University of Nottingham. He is an IEEE PELs 'Member at Large' and an IEEE PELs Distinguished Lecturer. He has published 400 academic publications in leading international conferences and journals. 